\title{
Evaluation of endophyte toxin production and its interaction with transgenic perennial ryegrass (Lolium perenne L.) with altered expression of fructosyltransferases.
}

\section{Paula Andrea Giraldo ${ }^{1,2}$, Carly Elliott ${ }^{3}$ Pieter Badenhorst ${ }^{3,4}$, Gavin Kearney $^{5}$, German C. Spangenberg ${ }^{2,4}$, Noel O.I. Cogan ${ }^{2,4}$, Kevin F. Smith ${ }^{1,3^{*}}$}

${ }^{1}$ The University of Melbourne, Faculty of Veterinary and Agricultural Sciences, Parkville, Victoria 3010, Australia.

${ }^{2}$ Agriculture Victoria Research, AgriBio, The Centre for AgriBiosciences, Bundoora, Melbourne, Victoria 3083, Australia.

${ }^{3}$ Agriculture Victoria Research, Hamilton, Victoria 3300, Australia.

${ }^{4}$ School of Applied Systems Biology, La Trobe University, AgriBio, The Centre for AgriBiosciences, Bundoora, Melbourne, Victoria 3083, Australia.

${ }^{5}$ Paynes Rd, Hamilton, Victoria 3300, Australia.

*Corresponding author: e-mail: kfsmith@unimelb.edu.au

Acknowledgments: The research described here was funded by the Victorian Department of Economic Development, Jobs, Transport and Resources (DEDJTR). The authors would like to thank the Molecular Genomics, Molecular Phenomics and Molecular Plant Breeding teams for their support collecting and processing samples. Specially, Mr. Aaron Elkins and Mrs Michelle Drayton for their assistance analysing alkaloid concentrations and endophyte infection. 


\section{Abstract}

Alkaloid concentration of perennial ryegrass herbage is affected by endophyte strain and host plant genotype. However, previous studies suggest that associations between host and endophyte also depends on environmental conditions, especially those affecting nutrient reserves and that water-soluble carbohydrate (WSC) concentration of perennial ryegrass plants may influence grass-endophyte associations. In this study a single transgenic event, with altered expression of fructosyltransferase genes to produce high WSC and biomass, has been crossed into a range of cultivar backgrounds with varying Epichloë endophyte strains. The effect of the association between the transgenic trait and alkaloid production was assessed and compared with transgene free control populations. In the vast-majority of comparisons there was no significant difference between alkaloid concentrations of transgenic and non-transgenic plants within the same cultivar and endophyte backgrounds. There was no significant difference between $\mathrm{GOI}+$ (gene of interest positive) and GOl- (gene of interest negative) populations in Janthritrem response. Peramine concentration was not different between GOI+ and GOI- for 10 of the 12 endophytes-cultivar combinations. Cultivar Trojan infected with NEA6 and Alto with SE (standard endophyte) exhibited higher peramine and lolitrem B (only for Alto SE) concentration, in the control GOI- compared with GOI+. Similarly, cultivar Trojan infected with NEA6 and Alto with NEA3 presented higher ergovaline concentration in GOI-. Differences in alkaloid concentration may be attributable to an indirect effect in the modulation of fungal biomass. These results conclude that the presence of this transgenic insertion, does not alter the risk (toxicity) of the endophyte-grass associations. Endophyte-host interactions are complex and further research into associations with high WSC plant should be performed in a case by case basis.

Keywords: genetically modified, Epichloë, Lolium perenne L., higher-energy. 


\section{Introduction}

Perennial ryegrass (Lolium perenne L.) is one of the most important pasture grasses in temperate zones worldwide. This pasture plays a key role in providing the grazing feed-base for the dairy and red meat production industries. Ryegrass has remarkable characteristics that makes it popular, of which the most outstanding are high herbage yield and quality, favourable palatability and high grazing persistence (Yamada et al. 2005). Currently, digestibility and energy concentrations are key breeding targets, due to their potential to increase animal production through energy yield and increased intake.

Digestibility has low genetic heritability and has a large number of genes that control the trait. Measuring the trait simply and in large numbers is complex and requires laboratory based screening procedures to be used. As a result of these factors, limited gains have currently been realised by conventional breeding. Different transgenic approaches have been used to increase ryegrass energy, such as accumulation of water-soluble carbohydrates (WSC) in leaf blades (Panter et al. 2017), accumulation of lipids in the leaves (Winichayakul et al. 2008, 2013) and indirectly through improvement in fibre degradability (Faville et al. 2010). Moreover, an elevated concentration of WSC in grasses has been shown to increase milk and animal production (Smith et al. 1998b; Miller et al. 2001).

A perennial ryegrass cultivar with increased energy that was also adapted to Australian conditions could increase animal production in sheep, beef and dairy systems. (Ludemann et al. 2013; Smith et al. 1997). An arbitrary increase of $1 \mathrm{MJ} / \mathrm{Kg}$ of dry matter in metabolizable energy concentration of this grass, could lead to an increment of on farm operating profit between 40 and 54\% (Ludemann et al. 2015). Therefore, emerging technologies such as genetic-engineering and gene-editing are being used to improve WSC and digestibility in forage grasses.

Genetic variation in the expression of fructosyl transferases has been shown to lead to high WSC concentrations in perennial ryegrass (Rasmussen et al. 2014), that had previously been utilised by plant breeders to develop a range of 'high sugar' cultivars 
(Humphreys 1989a, b, c). These cultivars have been shown to have the potential to increase animal production, but issues such as regional adaptation, (Smith et al. 1998a; Smith et al. 2007) and the interaction of yield and carbohydrate with seasonal growth patterns and grazing management (Turner et al. 2015; Robins and Lovatt 2016; Chen et al. 2017), has meant that the expression of the trait and subsequent changes in animal performance have not always been consistent.

An alternative approach to selection is the use of genetic modification to improve pasture quality and energy concentration, through the alteration of the expression of fructosyltransferases in conjunction with photosynthetic promoters (Panter et al. 2017; Badenhorst et al. 2018). High energy ryegrass has been produced, through up-regulation of fructan biosynthesis in leaf blades and pseudo-stems (Panter et al. 2017). Glasshouse evaluations of these transgenic plants followed by field trials have suggested an increment between $0.6-1.7 \mathrm{MJ} / \mathrm{Kg}$ of dry matter in metabolizable energy, compared to their isogenic control (Badenhorst et al. 2018).

Genetically modified (GM) plants are required to undergo rigorous safety assessments, to provide an evaluation of the potential impact on human, animal and the environment prior to commercialisation. Risk assessment of GM cultivars or plants are required to include a detailed molecular characterization, development of tracking and tracing methodologies, assessments of allergenicity, as well as nutritional and toxicological studies. Although, perennial ryegrass is not pathogenic or capable of causing any disease in plants, humans or animals, it can contain a fungal endophyte, which does produce alkaloids that act as deterrents to insect herbivory, but also can affect utilisation as animal feed (Office of the Gene Technology Regulator, 2008) and as such any transgene needs to be assessed for its effect on the production of these toxins.

The endophyte of ryegrass is the asexual species of Epichloë (previously classified as the form genus Neotyphodium: Leuchtmann et al. 2014) that forms mutualistic relationships with their host. The endophyte gains shelter, nutrients and a means of transmission, while the plant gains increased protection from biotic stresses, mammalian and insect herbivores, and nematodes, as well as increased tolerance to abiotic stresses such as drought and lack of nutrients like soluble nitrogen 
(Hennessy et al. 2016; Bacon 1993). Such resistance against insect herbivorous is conferred through the accumulation of alkaloids, which can have anti-feeding and/or toxic effects.

Alkaloids produced by Epichloë endophytes are secondary metabolites that can be classified in four major groups; pyrrolopyrazine compound peramine (Tanaka et al. 2006), indole-diterpenes such as lolitrem B and janthitrem (Guerre 2016), ergot alkaloids (Guerre 2015) and lolines (Blankenship et al. 2001). Peramine and janthitrem I protect its host from invertebrate herbivore attack without detrimental effects to livestock, while lolitrem B is a potent tremorgen that makes it toxic to cattle, and ergovaline has a vasoconstrictor effect in mammals, but also deter feeding by insects so is beneficial at low levels.

Alkaloid profiles vary among different endophyte species and strains. Standard endophyte (SE), is a natural occurring endophyte present in perennial ryegrass (Lolium perenne, asexual Epichloë endophytes). SE produces lolitrem B which can cause ryegrass staggers and ergovaline which causes heat stress, therefore can be an animal health risk (Kaur et al. 2015). Development of endophyte strains with optimal alkaloid profiles are important in the livestock industry, as over expression of some alkaloids can cause losses in milk production and liveweight gain (Nicol and Klotz 2016). Therefore, it is essential to deliver the specific concentration of alkaloids, to prevent insect attack on plants, but to not affect animal wellbeing.

Some "novel" endophyte-grass host associations, in which alkaloids that act to deter insect herbivory are retained, but those that confer toxicity to mammalian grazers are absent or less abundant include; AR1 (Bultman and Bell 2003) that produces only peramine, NEA2 which produces peramine, ergovaline and low level of lolitrem B (van Zijll de Jong et al. 2008b), NEA3, NEA6 and NEA11 (van Zijll de Jong et al. 2008a), produce peramine and ergovaline, NEA12 (Kaur et al. 2015) and AR37 (AgResearch Ltd, Palmerston North, New Zealand) produce only janthitrem I. These endophyte strains are known to express no lolitrem B and ergovaline, or its production is at levels that do not stress the animal such that welfare and productivity are not compromised. However, further experiments evaluating the effect of these novel endophytes on animal welfare are required, since its effect in mammalian 
metabolism has not yet been well elucidated. Despite the complexity of grassendophyte associations the majority or the perennial ryegrass seed in Australia and New Zealand contains endophytes.

The type of endophyte strain and host genotype are the main determinant of alkaloid concentration. However, previous studies have suggested that relationships between host and endophyte depends on environmental conditions, especially those affecting resource availability such as WSC (Ryan et al. 2015). Those studies found a 50\% reduction in endophyte and alkaloid concentration when they used a cultivar bred for high WSC, compared with a conventional cultivar (Rasmussen et al. 2007). Factors that change alkaloid concentration may have effects on toxicity, invasion and species diversity (Liu et al. 2011; Ryan et al. 2015). Studying the effects of transgenic perennial ryegrass on endophyte concentration and alkaloid production is important, since it could alter the ecological or environmental context of host-endophyte interactions.

In the present study, a single transgenic event, conferring high-energy and enhanced biomass yield, that has been crossed into a range of cultivar backgrounds with varying endophytes is evaluated for its effect on alkaloid production, in comparison to the transgene free control populations. This study aims to quantify the effects of this single transgenic event on endophyte alkaloid productivity, provide guidance on future approaches of transgenic breeding requirements in relation to endophyte toxin evaluation, and assist in the comprehensive evaluation of a potentially commercialisable transgenic event. 


\section{Materials and methods}

\section{Generation and selection of the transgenic event}

Fructan biosynthesis genes were re-programmed through the transgenic manipulation of two genes involved in the catalyses of the first step in fructan biosynthesis (sucrose: sucrose 1-fructosyl transferase (1-SST)), and elongation of the growing fructan chain (6-glucose fructosyltransferase (6G-FFT)). For designing the SST-FFT fusion protein gene, the terminal codon (TAG) of the perennial ryegrass SST gene was removed and a rubisco promoter (enzyme involve in photosynthesis) was added to promote fructan accumulation in leaves. Description of the generation of the transgenic ryegrass plants with altered fructan biosynthesis is reported in Panter et al. (2017). Briefly, perennial ryegrass variety FLp418-20, was selected for use as donor material based on the observed shoot regeneration from embryogenic callus (EC) derived from mature seeds of FLp418 (PGG Wrightson Seeds, Christchurch, New Zealand). Clonal replicates of the genotype FLp418-20, were subjected to transformation with the vector backbone-free expression cassette cGRA000022 (supplement fig. S1). Biolistic-mediated DNA delivery to embryogenic callus from perennial ryegrass genotype FLp418-20 (called from now on as gene of interest negative GOI-), was used to generate the putative primary T0 transgenic perennial ryegrass event (called from now on as gene of interest positive $\mathrm{GOI}+$ ). Based on good agronomical performance, increased fructan concentration and altered nutritive characteristics the event 10 containing the cGRA000022 cassette was selected for further analysis. Event 10 field evaluation and its further development using molecular breeding technologies are described in Badenhorst et al. (2018).

\section{Cultivar-endophyte combination selection}

Fifteen cultivar-endophyte combinations were assessed (supplementary material table S2). Seeds of perennial ryegrass cv. Alto, Bronsyn and Trojan containing the common standard endophyte (SE) strain (previously designated standard toxic, ST) (van Zijll de Jong et al. 2008a), two commercial endophytes; AR1 (AgResearch Ltd, 
Palmerston North, New Zealand), NEA2, (van Zijll de Jong et al. 2008b), and four pre-commercial strains; NEA3 NEA6 (van Zijll de Jong et al. 2008a), NEA11, and NEA12 (Kaur et al. 2015), were obtained from New Zealand Agriseeds Ltd, Christchurch, New Zealand. A total of 20 seeds from each accession were germinated and maintained under glasshouse conditions (with natural day-lengths and mean temperature of $22^{\circ} \mathrm{C}$; DEDJTR Hamilton) at the Victorian Department of Economic Development, Jobs, Transport and Resources (DEDJTR), Hamilton Centre, Victoria, Australia.

\section{Crossing strategy}

Description of the full molecular plant breeding strategy implemented for ryegrass with altered fructan biosynthesis is reported in Badenhorst et al. $(2016,2018)$. Briefly, T0 event plants were crossed with ryegrass cv. Alto, Bronsyn and Trojan containing the selected endophyte strains. The T0 event plants were used as the pollen donor in the pair cross and seed was only harvested from the non- transgenic plant that received pollen, to allow for the maternal transfer of endophyte to the progeny. Seeds from the non-transgenic recipient genotypes (q-non-transgenic genotype/ $/$-transgenic event) were germinated in glasshouse.

\section{Gene of interest (GOI) detection}

Fresh leaves $(\sim 1 \mathrm{~g})$ were harvested into a $50-\mathrm{mL}$ centrifuge tube and snap-frozen in liquid nitrogen. Samples were freeze-dried for $24 \mathrm{~h}$ (Genesis 25XL Freeze- Dryer, VirTis, Canton, MA, USA). Genomic DNA was extracted from $300 \mathrm{mg}$ of plant material using the DNeasy Plant Mini Kit (QIAGEN) per manufacturer's protocol.

The presence of the endogenous histone $\mathrm{H} 3$ gene ( $\mathrm{LpHisH} 3$ ) and the gene of interest (GOI) was detected by real-time PCR, using specific oligonucleotide primer pairs (supplementary data, table S3) and SYBR Green chemistry (Roche Diagnostics, Basel, Switzerland). PCR cycling conditions were $95^{\circ} \mathrm{C}$ for $10 \mathrm{~min}, 40$ cycles of $95^{\circ} \mathrm{C}$ for $30 \mathrm{secs}$ and $63.7^{\circ} \mathrm{C}$ for $1 \mathrm{~min}$. Results were scored in comparison to positive (plasmid DNA) and negative (non-transgenic plant DNA, no-template) 
control templates with the endogenous histone $\mathrm{H} 3$ gene (LpHisH3) included as a control (Panter et al. 2017).

\section{Endophyte detection}

Three random tillers from each plant were harvested by cutting $1 \mathrm{~cm}$ from the base, then pooled together, placed into collection microtube racks (Qiagen $\mathrm{GmbH}$, Hilden, Germany) and freeze-dried (Genesis 25XL Freeze- Dryer, VirTis, Canton, MA, USA) for 48 hours. DNA extraction was performed using the DNeasy Plant 96-kit (Qiagen, Hilden, Germany) per the manufacturer's protocol.

Multiplex PCR reactions were set up with $0.2 \mathrm{mM}$ dNTPs, $250 \mathrm{nM}$ of each of the six oligonucleotides used for endophyte detection, 0.5 units of Immolase DNA polymerase (Bioline, London, UK) and $1 \times$ Immolase buffer (Bioline) and $25 \mathrm{ng}$ of plant DNA, 10 ng of positive control endophyte DNA or water as the template in a 20 $\mu \mathrm{L}$ reaction volume. Cycling conditions were: $95^{\circ} \mathrm{C}$ for $10 \mathrm{~min}, 10$ cycles of $94^{\circ} \mathrm{C}$ for $30 \mathrm{sec}, 65^{\circ} \mathrm{C}-1^{\circ} \mathrm{C}$ per cycle and $72^{\circ} \mathrm{C}$ for $1 \mathrm{~min}, 20$ cycles of $94^{\circ} \mathrm{C}$ for $30 \mathrm{sec}, 55^{\circ} \mathrm{C}$ for $30 \mathrm{sec}$ and $72^{\circ} \mathrm{C}$ for $1 \mathrm{~min}$ followed by a $4^{\circ} \mathrm{C}$ hold. Reactions containing plant DNA and endophyte DNA were diluted $1: 10$ and 1:100 respectively with nucleasefree water. Aliquots of diluted PCR reactions $(2 \mathrm{~mL})$ were combined with $7.95 \mathrm{~mL}$ of Hi DiTM Formamide (Life Technologies, Carlsbad, CA) and $0.05 \mathrm{~mL}$ of the GenescanTM 500LIZTM molecular weight standard (Life Technologies).

PCR products were analysed using an Applied Biosystems 3730 DNA AnalyzerTM (Life Technologies), and raw results were scored against predicted product sizes to identify endophytes with GeneMapperTM v 3.7 software (supplementary data, table S4 and S5). Endophyte-specific SSR (Single Sequence Repeat) genotyping and cluster analysis was performed as described by Kaur et al. (2015).

\section{Trial design and quantitative endophyte alkaloid analysis}

Once all progeny was sampled and screened for the presence of GOI and endophyte strain, the associations were arranged in a randomised block design created in GENSTAT (Windows 13th Edition; VSN International Ltd, Hemel 
Hempstead, UK) (Badenhorst P.E. 2014). After 6 weeks in the randomised design and under controlled conditions, each plant was harvested approximately $5 \mathrm{~cm}$ from the base and freeze-dried (VirTis Genesis 25XL:SP Scientific, Stone Ridge, NY, USA) for $48 \mathrm{~h}$, followed by grinding to $1 \mathrm{~mm}$ with a Tecator Cyclotec 1093 sample mill (Foss, Hillerød, Denmark).

For the quantitative alkaloid analysis, samples were extracted twice using $1 \mathrm{~mL}$ of methanol:water (80:20, v:v) as the solvent in $20 \mathrm{mg}$ of freeze-dried, ground material. Both supernatants were mixed, dried down and reconstituted in $200 \mu \mathrm{L}$ methanol:water $(80: 20, \mathrm{v}: \mathrm{v})$. For quality control purposes, ryegrass samples cultivar Trojan with standard endophyte were used. Quantification and identification of alkaloids were determined by liquid chromatography mass spectrometry (LC-MS).

Series of commercial (peramine nitrate and ergotamine) and in-house isolated (Iolitrem B) standard solutions at concentrations of 10, 25, 50, 100, 250, 1000 and $2000 \mathrm{ng} / \mathrm{mL}$ were prepared and used to construct concentration curves. An Agilent 1290 UHPLC with a $150 \mathrm{~mm} \times 2.1 \mathrm{~mm}$ Themo Hypersil Gold $1.9 \mu \mathrm{m}$ HPLC column, was used for the analysis of $3 \mu \mathrm{L}$ aliquots of each sample extract. A gradient mobile phase with a mixture of two solvents: $0.1 \%$ formic acid in water (solvent $A$, Thermo Scientific) and $0.1 \%$ formic acid in acetonitrile (solvent B, Thermo Scientific) was used with a flow rate of $0.3 \mathrm{~mL} / \mathrm{min}$. Initial conditions were $98 \%$ solvent $A$ before initiating a linear gradient to $0 \%$ solvent $A$ over 11 minutes, and this was maintained for 4 minutes before returning to the initial gradient conditions. Compounds were identified using a Thermo Fisher Orbitrap Velos mass spectrometer (Waltham, MA, USA; Thermo, Bremen, Germany), operating in positive ESI for data acquisition. The masses were acquired in the range of 150-2000 amu and the limit of quantification for the analysis was $1.2 \mathrm{ng} / \mathrm{ml}$ and limit of detection $0.36 \mathrm{ng} / \mathrm{mL}$. Relative quantification (expressed as peak area) is presented for janthitrem I in the absent of standards for this compound, as well as relative quantification of ergovaline relative to ergotamine concentration. For peramine and lolitrem $B$ quantitative results with matched standards were calculated.

\section{Statistical analysis}


Statistical analysis of derived data was performed using the residual maximum likelihood (REML) model within GENSTAT. Variables were natural log transformed prior to analysis to stabilize the variance. The model used for analysis was a mixed model with endophyte strain, cultivar and host genotype fitted as fixed effects and experimental design factors such as row and column were fitted as random effects. Each alkaloid analysed was measured only in the strain known to produce that alkaloid. The least significant difference (I.s.d.) at $P=0.05$ was generated to test for effects arising from differences between endophytes and between host genotypes within each association. Comparisons were made between gene of interest positive $(\mathrm{GOI}+)$ and negative (GOI-) treatments within the same cultivar-endophyte combination. 


\section{Results}

The previously generated event 10 with expression of cGRA000022 cassette was used as input for the detailed evaluation of transgene $\mathrm{x}$ host $\mathrm{x}$ endophyte evaluation. Seeds of perennial ryegrass (Lolium perenne L.) cv. Alto, Bronsyn and Trojan containing the common standard endophyte (SE) and six commercial endophytes were germinated to use as the selected recipient genotypes. The endophyte incidence in the potential recipients was 98\%. Selected plants that contained endophyte were used in pair-crosses with selected T0 event plants.

Genotypic analysis was performed on $\mathrm{T} 1 / \mathrm{F} 1$ progenies ( $\mathrm{GOI}+$ ) produced from crosses and non-transgenic control samples (GOI-), to identify transgene positive and negative plants. A total of 302 plants were also screened for endophyte presence and identity. Only 3 plants were excluded from further analysis due to failure to identify endophyte presence, based on a collection of diagnostic SSR markers. Therefore, 299 plants were confirmed as endophyte positive $\left(E_{+}\right)$and incidence for the T1/F1 progenies was $99 \%$.

The most prevalent endophyte was AR1, occurring in 36 plants of cultivar Alto (21 GOI- and $15 \mathrm{GOI}$ ), 26 in cultivar Trojan (14 GOI- and $12 \mathrm{GOI}$ ) and 20 in cultivar Bronsyn (12 GOI- and $6 \mathrm{GOI}$ ) (supplementary material table S2). The strain NEA3 presented the lowest incidence in symbiosis with cultivar Trojan (4 plants; 2 GOIand $2 \mathrm{GOI}+$ ), these were excluded from the experiment due to insufficient experimental replicates. However, the association between NEA3 and cultivar Alto occurred in 27 plants (17 GOI- and $10 \mathrm{GOI}+$ ).

All GOI+ and GOl- plants carrying candidate endophytes were subjected to a qualitative analysis for production of peramine, lolitrem B, and ergovaline. Janthritrem response was analysed separately and was semi-quantitative. Each alkaloid was measured only in the strain known to produce it, as described in supplementary material (table S6). Data were logarithmic transformed $\left(\log _{\mathrm{e}}\right)$ in the absence of a normal distribution. Different constant values were added to each alkaloid per its residual distribution (table 1). 
Results of transformed means and the least significant differences (LDS) are presented in table 1. All significant differences reflected lower alkaloid concentration for $\mathrm{GOI}+$ compare with GOI-. Peramine concentrations (reported in parts per million, ppm) for GOI- samples was higher than $\mathrm{GOI}+$ in most combinations, although these differences were not significant (Fig. 1). The Trojan-NEA6 combination in the control (GOI-) was significantly higher than the $\mathrm{GOI}+$ combination, producing $21.3 \mathrm{ppm}$ and $8.0 \mathrm{ppm}$ of peramine respectively. Similarly, in Alto-SE peramine concentration was 64.2 and 25.2 ppm for GOI- and GOI+ respectively.

Even though the aim of this study was evaluating the effect of $\mathrm{GOI}$ on alkaloid production, differential responses within cultivars and endophyte strains were apparent. For instance, peramine concentration in a single GOI- cultivar, Trojan with AR1 was $47.3 \mathrm{ppm}$ higher than with NEA2 (56.5 ppm and $9.2 \mathrm{ppm})$ and SE with cultivar Bronsyn was $25.4 \mathrm{ppm}$ lower than Alto (38.8 ppm and $64.2 \mathrm{ppm}$ ).

Lolitrem B (Fig. 2.) with the standard endophyte strain (SE) synthesized considerably higher amounts of this alkaloid compared to NEA2, which is consistent with known expression levels. The combination of Bronsyn-NEA2 and Bronsyn-SE, produced similar concentration of lolitrem B between $\mathrm{GOI}+$ and $\mathrm{GOI}$-. In contrast, lolitrem B concentration for Alto-SE was significantly higher for GOI- than for $\mathrm{GOI}+(19.9 \mathrm{ppm}$ and $2.1 \mathrm{ppm})$. Trojan-NEA2 also presented higher concentration for GOI-, but the difference was not significant.

For most endophyte-cultivar combinations, ergovaline concentrations were the same or higher for GOI- than GOI+ (Fig. 3.). Conversely, for Alto-NEA11, Trojan-NEA11, Trojan-NEA2 and Bronsyn-SE combinations, GOl+ produced lower levels of ergovaline than GOI-, however these differences were not statistically significant when comparing $\mathrm{GOI}+$ and $\mathrm{GOI}$ - samples. Trojan-NEA6 showed the highest significant difference in ergovaline concentration for GOI- (14.2 ppm), compare with $\mathrm{GOI}+(3.7 \mathrm{ppm})$.

Janthritrem is a less common alkaloid and there are not commercially available standards for this compound, therefore results are expressed as response (relative 
peak areas). The NEA12 strain was present in cultivar Alto, Bronsyn, and Trojan (Fig. 4.). Cultivar Trojan and Bronsyn inoculated with NEA12 presented similar responses between $\mathrm{GOI}+$ and GOI-. However, in the combination Alto-NEA12, GOI+ showed higher janthritrem response than GOI-, but there were no statistically significant differences identified from any combination. 


\section{Discussion}

High-energy ryegrass has been created by altering fructan accumulation patterns, using fructosyltransferases genes (1-SST and 6G-FFT) that are expressed under the control of a light-regulated promoter fragment ( $L p R b c S)$ (Panter et al. 2017). The self-incompatible outcrossing nature of perennial ryegrass, makes transgenic breeding a complex process. To fix the transgene within the outcrossing population, an introgression step had to be employed in the breeding system. The detailed transgenic breeding strategy used for high-energy ryegrass is described in Badenhorst et al. (2018).

To allow endophyte and transgene transfer to the progeny, pair crosses where the pollen donor was the T0 event plants and seed was only harvested from the nontransgenic potential recipients were performed, as endophyte is maternally inherited. T1/F1 progenies within different backgrounds were confirmed to have the transgene loci, following a Mendelian inheritance of a single dominant allele with an expected $1: 1$ segregation ratio for the transgene.

The incidence level of fungal endophyte in the T1/F1 progenies was close to absolute, possibly as the seed was supplied from a commercial seed supplier and they guarantee an incidence higher than $80 \%$. These results highlight the importance of specific selection for host-endophyte associations, based on the interaction between host and endophyte genotype (Wiewióra, Żurek, and Pańka, 2015).

Genetic factors affecting endophyte-host associations have been researched in the last decade. For instance, genetic studies have suggested that qualitative variations in alkaloid profiles are mostly caused by endophyte genotype, while quantitative variations are related with host genotype (Ekanayake et al. 2017; Kaur et al. 2015). However, some studies have suggested that the degree of mutual benefit for endophytic fungi and their hosts genotype can be also conditional on environmental factors such as nutrient availability, especially those affecting WSC concentration. 
Rasmussen et al. $(2007,2008)$ proposed that other factors such as plant leaf carbohydrate content, nitrogen supply and competition with other fungal symbionts can modify the quantitative alkaloid profile in Lolium perenne L. Rasmussen et al. (2007) compared a marketed high-WSC cultivar ('AberDove') with a "normal WSC' cultivar (Fennema), inoculated them with AR1 and AR37 strains and found both endophyte concentration and alkaloid production was reduced by $50 \%$ in AberDove. However, following detailed WSC measurements of the inoculated material no significant differences were found. They hypothesized that such decrease was due to differences between genotypes within and between both cultivars.

Subsequent studies of the same group investigated whether differences were due to the effects of altered carbohydrates, or host genetic background, by growing multiple cultivars in both high- WSC trait expression and non-expression conditions (using light/temperature treatments). Concluding that low molecular weight (LMW) carbohydrates had a small effect, explaining only $<6 \%$ of the variation in endophyte concentration and the endophyte reduction was caused by differences in compatibility (i.e. differences in the genetic background of cultivars resulting in variable 'affinities' for endophytic infection) (Ryan et al. 2015).

As mentioned earlier, endophyte and host genetic background has an important role in endophyte-host associations and there is a lot of genetic diversity among ryegrass cultivars and endophyte strains. It is the reason why in this study the effect of transgenic high WSC cultivar on alkaloid profile was compared within the same cultivar and endophyte strain, to eliminate those genetic factors.

The quantitative alkaloid analysis of different cultivar-endophyte associations in this study, indicated no significant effect of $\mathrm{GOl}+$ and $\mathrm{GOI}$ - plants in most combinations. Though, peramine concentration in $\mathrm{GOI}+$ decreased by $62 \%(21.3-8.0 \mathrm{ppm})$ and 61\% (64.2-25.2 ppm) in Trojan-NEA6 and Alto-SE respectively. Ergovaline also decreased in $\mathrm{GOI}+$ with Trojan-NEA6 by $74 \%$, (14.2-3.7 ppm), Alto-NEA3 by $54 \%$ (9.0-4.1 ppm), Bronsyn-NEA11 by 58\% (3.3-1.4 ppm), and Alto-SE by $77 \%$ (3.1-0.7 ppm). For lolitrem B only Alto-SE in GOI+ decrease significantly by $89 \%(19.9-2.1)$ and janthritrem response did not present differences between $\mathrm{GOI}+$ and $\mathrm{GOI}$ - 
Differences in peramine, ergovaline and lolitrem B for Alto-SE and Trojan-NEA6 might not be related with the capacity of alkaloid biosynthesis in $\mathrm{GOI}+$ plants, but potentially due to an indirect effect in the modulation of fungal biomass. The phenomenon called "dilution effect", occurs when an external factor stimulates the growth of the grass plant more than it stimulates the growth of the fungus and has previously been reported by Lane et al. (1997), so that the plant and fungal growth rate are out of synchrony. Transgenic ryegrass plants with altered expression of fructosyltransferases have consistently shown increase in metabolizable energy, up to $1.7 \mathrm{MJ} \mathrm{ME} \cdot \mathrm{kg} \mathrm{DM}^{-1}$ in selected T0 events compared with the control genotype, and higher biomass yields, compared to the untransformed control and a commercial high WSC ryegrass (Badenhorst et al. 2018).

The reduction in peramine concentration for Trojan-NEA6 with $\mathrm{GOI}+$ may cause lower pasture protection against insects, since maintenance of a high peramine concentration, minimum of $15-20 \mathrm{ppm}$, is considered crucial for effective insect resistance (Popay et al. 2003). However, Alto-SE with GOI+ may still deter insect as its concentration was $25.2 \mathrm{ppm}$. There is no a consistent evidence that reprogramming of the expression of fructan biosynthesis genes in ryegrass can alter the association between the host plants and the resident endophyte strain in a positive or negative way. As evaluation of the interaction and alkaloid levels are performed in every new cultivar, agronomic potential of transgenic perennial ryegrass with different novel endophytes should be assessed on a case by case basis, and these data suggest that no new testing regimes are required over and above what is already performed and considered standard practice for ryegrass breeding. 


\section{Conclusion}

Increased accumulation of fructan in leaf blades of perennial ryegrass would have a potential economic benefit in livestock industry. The presence of a transgenic cassette to enhance water-soluble carbohydrates had little effects, compare with the impact of host and endophyte strain genotype on endophyte persistence and quantitative alkaloid analysis. The few observed changes in peramine and ergovaline concentration does not alter the balance of risk (toxicity) of endophyte-grass associations under the present experimental conditions and are possibly associated with the highest growth rate in genetically enhanced ryegrass. Endophyte-host interactions are complex and further research into associations with high WSC plant is needed. 


\section{References}

Bacon CW (1993) Abiotic stress tolerances (moisture, nutrients) and photosynthesis in endophyte-infected tall fescue. Agriculture, ecosystems \& environment 44(14):123-141.

Badenhorst PE (2014) Phenomic Evaluation and molecular breeding of field-grown transgenic perennial ryegrass (Lolium perenne L.) with altered fructan biosynthesis. $\mathrm{PhD}$ thesis, La Trobe University, Australia.

Badenhorst PE, Panter S, Palanisamy R, Georges S, Smith KF, Mouradov A, Mason J, Spangenberg GC (2018) Molecular breeding of transgenic perennial ryegrass (Lolium perenne L.) with altered fructan biosynthesis through the expression of fructosyltransferases. Molecular Breeding 38:21. https://doi.org/10.1007/s11032-0180776-3

Badenhorst PE, Smith KF, Spangenberg G (2016) Development of a molecular breeding strategy for the integration of transgenic traits in outcrossing perennial grasses. Agronomy 6(4):56. https://doi.org/10.3390/agronomy6040056

Blankenship JD, Spiering MJ, Wilkinson HH, Fannin FF, Bush LP, and Schardl CL (2001). Production of loline alkaloids by the grass endophyte, Neotyphodium uncinatum, in defined media. Phytochemistry 58:395-401. https://doi.org/10.1016/S0031-9422(01)00272-2

Bultman TL, Bell GD (2003) Interaction between fungal endophytes and environmental stressors influences plant resistance to insects. Oikos 103(1):182190.

Chalmers J, Lidgett A, Cummings N, Cao Y, Forster J, Spangenberg G (2005) Molecular genetics of fructan metabolism in perennial ryegrass. Plant Biotechnology Journal 3(5):459-474. 
Chen A, Bryant RH, Edwards GR (2017) Milk production and composition of dairy cows grazing two perennial ryegrass cultivars allocated in the morning and afternoon. Animal Production Science 57:1507-1511.

Ekanayake P N, Kaur J, Tian P, Rochfort S J, Guthridge K M, Sawbridge T I, Spangenberg GC, Forster JW (2017) Genomic and metabolic characterisation of alkaloid biosynthesis by asexual Epichloë fungal endophytes of tall fescue pasture grasses. Genome 60(6):496-509.

Faville MJ, Richardson K, Gagic M, Mace W, Sun XZ, Harrison S, Knapp K, Jahufer MZZ, Palanisamy R, Pirlo S, Johnson R (2010) Genetic improvement of fibre traits in perennial ryegrass. In proceedings of the New Zealand Grassland Association 72:71-78.

Guerre P (2015) Ergot alkaloids produced by endophytic fungi of the genus Epichloë. Toxins 7(3): 773-790.

Guerre P (2016) Lolitrem B and indole diterpene alkaloids produced by endophytic fungi of the genus Epichloë and their toxic effects in livestock. Toxins 8(2):47. https://doi.org/10.3390/toxins8020047

Hennessy LM, Popay AJ, Finch, SC, Clearwater MJ, Cave VM (2016) Temperature and plant genotype alter alkaloid concentrations in ryegrass infected with an Epichloë endophyte and this affects an insect herbivore. Front Plant Sci. 7:1097. https://doi.org/10.3389/fpls.2016.01097

Humphreys MO (1989a) Water-soluble carbohydrates in perennial ryegrass breeding. I. Genetic differences among cultivars and hybrid progeny grown as spaced plants. Grass and Forage Science 44:231-236.

Humphreys MO (1989b) Water-soluble carbohydrates in perennial ryegrass breeding. II. Cultivar and hybrid progeny performance in cut plots. Grass and Forage Science 44:237-244. 
Humphreys MO (1989c) Water-soluble carbohydrates in perennial ryegrass breeding. III. Relationships with herbage production, digestibility and crude protein content. Grass and Forage Science 44:423-430.

Kaur T, Singh B, Kaur A, Kaur S (2015). Endophyte-mediated interactions between cauliflower, the herbivore Spodoptera litura, and the ectoparasitoid Bracon hebetor. Oecologia 179(2):487-494.

Lane GA, Tapper BA, Davies E, Hume DE, Latch GCM, Barker DJ, Easton HS, Rolston MP (1997) Effect of growth conditions on alkaloid concentrations in perennial ryegrass naturally infected with endophyte. In: Bacon CW, Hill AC, eds. Neotyphodium/grass interactions. New York, NY, USA: Plenum Press, 179-182.

Leuchtmann A, Bacon CW, Schardl CL, White JF, Jr, Tadych M. (2014). Nomenclatural realignment of Neotyphodium species with genus Epichloë. Mycologia 106:202-215. https://doi.org/10.3852/13-251

Liu Q, Parsons AJ, Xue H, Fraser K, Ryan GD, Newman JA, Rasmussen S (2011) Competition between foliar Neotyphodium lolii endophytes and mycorrhizal Glomus spp. fungi in Lolium perenne depends on resource supply and host carbohydrate content. Funct Ecol 25:910-920.

Ludemann C L, Cullen B R, Malcolm B, Smith KF (2013) Economic values of changes in energy concentration of pasture in contrasting temperate dairy regions in Australia. Australian Farm Business Management Journal 10:1-15.

Ludemann Cl, Eckard RJ, Cullen BR, Jacobs JL, Malcolm B, Smith K F (2015) Higher energy concentration traits in perennial ryegrass (Lolium perenne L.) may increase profitability and improve energy conversion on dairy farms. Agricultural Systems 137:89-100.

Miller LA, Moorby JM, Davies DR, Humphreys MO, Scollan ND, MacRae JC, Theodorou MK (2001) Increased concentration of water-soluble carbohydrate in 
perennial ryegrass (Lolium perenne L.): milk production from late-lactation dairy cows. Grass and Forage Science 56(4):383-394.

Nicol AM, Klotz JL (2016) Ergovaline, an endophytic alkaloid. 2. Intake and impact on animal production, with reference to New Zealand. Animal Production Science 56(11):1775-1786.

Panter S, Mouradov A, Badenhorst P, Martelotto L, Griffith M, Smith KF, Spangenberg $G$ (2017) Re-programming photosynthetic cells of perennial ryegrass (Lolium perenne $L$ ) for fructan biosynthesis through transgenic expression of fructan biosynthetic genes under the control of photosynthetic promoters. Agronomy 7(2):36. https://doi.org/10.3390/agronomy7020036

Popay AJ, Hume DE, Davis KL, Tapper BA (2003) Interactions between endophyte (Neotyphodium spp.) and ploidy in hybrid and perennial ryegrass cultivars and their effects on Argentine stem weevil (Listronotus bonariensis). New Zealand Journal of Agricultural Research 46:311-319. doi:10.1080/00288233.2003.9513559

Rasmussen S, Parsons AJ, Bassett S, Christensen MJ, Hume DE, Johnson LJ, Johnson RD, Simpson WR, Stacke C, Voisey CR, Xue H (2007) High nitrogen supply and carbohydrate content reduce fungal endophyte and alkaloid concentration in Lolium perenne. New Phytologist 173(4):787-797.

Rasmussen S, Parsons AJ, Fraser K, Xue H, Newman JA (2008) Metabolic profiles of Lolium perenne are differentially affected by nitrogen supply, carbohydrate content, and fungal endophyte infection. Plant physiology 146(3):1440-1453.

Rasmussen S, Parsons AJ, Xue H, Liu Q, Jones CS, Ryan GD, Newman JA (2014) Transcript profiling of fructan biosynthetic pathway genes reveals association of a specific fructosyltransferase isoform with the high sugar trait in Lolium perenne. Journal of Plant Physiology 171:475-485. 
Robins JG, Lovatt AJ (2016) Cultivar by environment effects of perennial ryegrass cultivars selected for high water soluble carbohydrates managed under differing precipitation regimes. Euphytica 208:571-581.

Ryan GD, Rasmussen S, Parsons AJ, Newman JA (2015) The effects of carbohydrate supply and host genetic background on Epichloë endophyte and alkaloid concentrations in perennial ryegrass. Fungal Ecology 18:115-125.

Smith KF, Kearney GA, Culvenor RA (1998a) The use of repeated measurements analysis for the evaluation of seasonal variation in the dry matter yield and nutritive value of perennial ryegrass (Lolium perenne L.) cultivars. Australian Journal of Experimental Agriculture 38:145-154.

Smith KF, Reed KFM, Foot JZ (1997) An assessment of the relative importance of specific traits for the genetic improvement of nutritive value in dairy pasture. Grass and Forage Science 52:167-175.

Smith KF, Simpson RJ, Oram RN, Lowe KF, Kelly KB, Evans PM, Humphreys MO (1998b) Seasonal variation in the herbage yield and nutritive value of perennial ryegrass (Lolium perenne L.) cultivars with high or normal herbage water-soluble carbohydrate concentrations grown in three contrasting Australian dairy environments. Australian Journal of Experimental Agriculture 38:821-830.

Smith KF, Stewart A, Spangenberg G (2007) Breeding high energy grasses for Australia and New Zealand. In New Zealand Grassland Association 69:173-177.

Tanaka A, Christensen MJ, Takemoto D, Park P, Scott B (2006) Reactive oxygen species play a role in regulating a fungus-perennial ryegrass mutualistic interaction. The Plant Cell 18(4):1052-1066.

Tizaoui K, Kchouk ME (2012) Genetic approaches for studying transgene inheritance and genetic recombination in three successive generations of transformed tobacco. 
Genetics and Molecular Biology 35(3):640-649. http://doi.org/10.1590/S141547572012000400015

Turner LR, Donaghy DJ, Pembleton KG, Rawnsley RP (2015) Longer defoliation interval ensures expression of the 'high sugar' trait in perennial ryegrass cultivars in cool temperate Tasmania, Australia. Journal of Agricultural Science 153:995-1005.

van Zijll de Jong E, Dobrowolski MP, Bannan NR, Stewart AV, Smith KF, Spangenberg GC, Forster JW (2008a). Global genetic diversity of the perennial ryegrass fungal endophyte Neotyphodium lolii. Crop Science 48(4):1487-1501.

van Zijll de Jong E, Dobrowolski MP, Sandford A, Smith KF, Willocks MJ, Spangenberg GC, Forster JW (2008b) Detection and characterisation of novel fungal endophyte genotypic variation in cultivars of perennial ryegrass (Lolium perenne L.). Australian Journal of Agricultural Research 59(3):214-221.

Wiewióra B, Żurek G, Pańka D (2015) Is the vertical transmission of Neotyphodium Iolii in perennial ryegrass the only possible way to the spread of endophytes? PloS one 10(2); e0117231.

Winichayakul S, Cookson R, Scott R, Zhou J, Zou X, Roldan M, Richardson K, Roberts N (2008) Delivery of grasses with high levels of unsaturated, protected fatty acids. In Proc NZ Grassland Assoc 70:211-216.

Winichayakul S, Scott RW, Roldan M, Hatier JHB, Livingston S, Cookson R, Curran AC, Roberts NJ (2013) In vivo packaging of triacylglycerols enhances Arabidopsis leaf biomass and energy density. Plant Physiology 162(2):626-639.

Yamada T, Forster JW, Humphreys MW, Takamizo T (2005) Genetics and molecular breeding in Lolium/Festuca grass species complex. Grassland Science 51(2):89106. 


\section{Table and figure legends}

Table 1: Transformed means with natural logarithm: $E=$ endophyte; $\mathrm{GOI}+=$ gene of interest positive; GOI- = gene of interest negative; LSD = least significant difference.

Fig. 1. Peramine concentration of each cultivar-endophyte combination for transgenic lines in dark grey and non-transgenic lines in clear grey. Bars are backtransformed means. a $b$ different letters indicate significant differences at $\mathrm{P}<0.05$. $\mathrm{GOI}+=$ gene of interest positive; $\mathrm{GOI}$ - = gene of interest negative

Fig. 2. Lolitrem B concentration of each cultivar-endophyte combination for transgenic lines in dark grey and non-transgenic lines in clear grey. Bars are backtransformed means. $\mathrm{GOI}+=$ gene of interest positive; $\mathrm{GOI}-=$ gene of interest negative

Fig. 3. Ergovaline concentration of each cultivar-endophyte combination for transgenic lines in dark grey and non-transgenic lines in clear grey. Bars are backtransformed means. a $b$ different letters indicate significant differences at $P<0.05$. $\mathrm{GOI}+$ = gene of interest positive; GOI- = gene of interest negative

Fig. 4. Janthritrem response of each cultivar-endophyte combination for transgenic lines in dark grey and non-transgenic lines in clear grey. Bars are back-transformed means. $\mathrm{GOl}+=$ gene of interest positive; $\mathrm{GOI}-$ = gene of interest negative 
Table 1: Transformed means: $\mathrm{E}=$ endophyte; $\mathrm{GOI}+=$ gene of interest positive; $\mathrm{GOI}-$ = gene of interest negative; $\mathrm{LSD}=$ least significant difference. $\mathrm{GOI}+=$ gene of interest positive; $\mathrm{GOI}$ - = gene of interest negative

\begin{tabular}{|c|c|c|c|c|c|}
\hline Trait & Transformation & Cultivar-E & $\mathrm{GOI+}$ & $\overline{\mathrm{GOl}-}$ & LSD \\
\hline \multirow[t]{12}{*}{ Peramine } & \multirow[t]{12}{*}{$\ln (y+10)$} & Alto-AR1 & 3.86 & 4.15 & 0.39 \\
\hline & & BronSyn-AR1 & 3.94 & 3.82 & 0.59 \\
\hline & & Trojan-AR1 & 4.30 & 4.20 & 0.46 \\
\hline & & Alto-NEA11 & 3.76 & 3.58 & 0.61 \\
\hline & & BronSyn-NEA11 & 3.36 & 3.44 & 0.48 \\
\hline & & Trojan-NEA11 & 3.25 & 3.32 & 0.64 \\
\hline & & BronSyn-NEA2 & 3.39 & 3.75 & 0.62 \\
\hline & & Trojan-NEA2 & 2.84 & 2.95 & 0.50 \\
\hline & & Alto-NEA3 & 3.54 & 3.62 & 0.48 \\
\hline & & Trojan-NEA6 & $2.89 \mathrm{~b}$ & $3.44 a$ & 0.51 \\
\hline & & Alto-SE & $3.56 \mathrm{~b}$ & $4.31 \mathrm{a}$ & 0.71 \\
\hline & & BronSyn SE & 3.98 & 3.89 & 0.54 \\
\hline \multirow[t]{4}{*}{ Lolitrem B } & \multirow[t]{4}{*}{$\ln (y+0.01)$} & BronSyn-NEA2 & -0.26 & -0.91 & 1.66 \\
\hline & & Trojan-NEA2 & 0.75 & 1.23 & 1.35 \\
\hline & & Alto-SE & $0.73 b$ & $2.99 a$ & 1.89 \\
\hline & & BronSyn SE & 2.45 & 2.39 & 1.46 \\
\hline \multirow[t]{9}{*}{ Ergovaline } & \multirow[t]{9}{*}{$\ln (y+0.08)$} & Alto-NEA11 & 1.04 & 0.60 & 0.98 \\
\hline & & BronSyn-NEA11 & $0.41 b$ & $1.23 a$ & 0.79 \\
\hline & & Trojan-NEA11 & 0.70 & 0.14 & 1.04 \\
\hline & & BronSyn-NEA2 & 0.16 & 0.82 & 1.00 \\
\hline & & Trojan-NEA2 & -1.25 & -1.37 & 0.81 \\
\hline & & Alto-NEA3 & $1.42 \mathrm{~b}$ & $2.21 \mathrm{a}$ & 0.79 \\
\hline & & Trojan-NEA6 & $1.32 b$ & $2.66 \mathrm{a}$ & 0.83 \\
\hline & & Alto-SE & $-0.22 b$ & $1.44 a$ & 1.15 \\
\hline & & BronSyn SE & 0.70 & 0.83 & 0.88 \\
\hline \multirow[t]{3}{*}{ Janthritrem } & \multirow[t]{3}{*}{$\ln (y)$} & Alto-NEA12 & 14.56 & 13.90 & 1.04 \\
\hline & & BronSyn-NEA12 & 13.52 & 13.64 & 0.85 \\
\hline & & Trojan-NEA12 & 13.64 & 13.96 & 0.78 \\
\hline
\end{tabular}




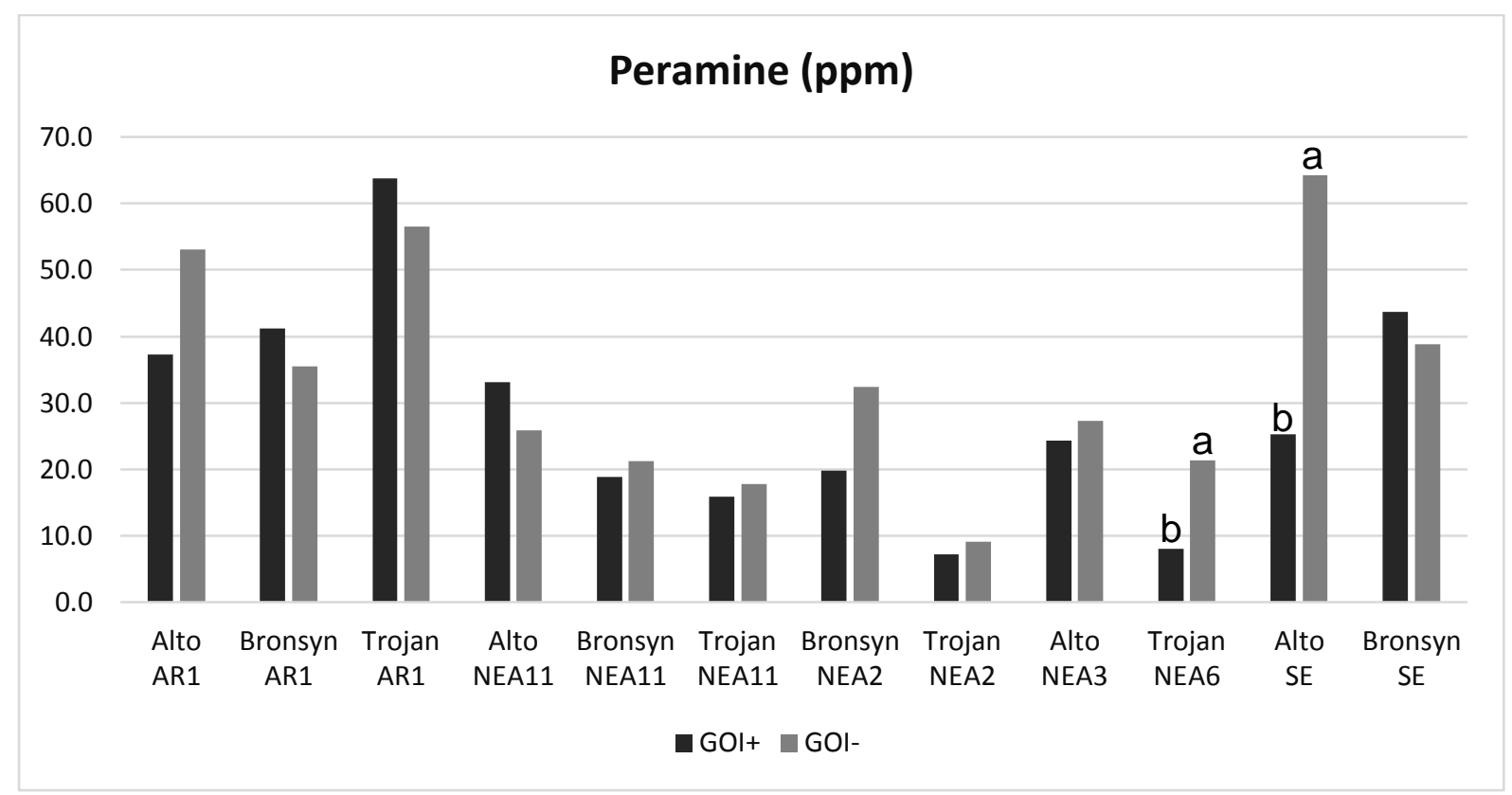

Fig. 1. Peramine concentration of each cultivar-endophyte combination for transgenic lines in dark grey and non-transgenic lines in clear grey. Bars are backtransformed means. $a b$ different letters indicate significant differences at $P<0.05$. $\mathrm{GOI}+$ = gene of interest positive; $\mathrm{GOI}$ - = gene of interest negative 


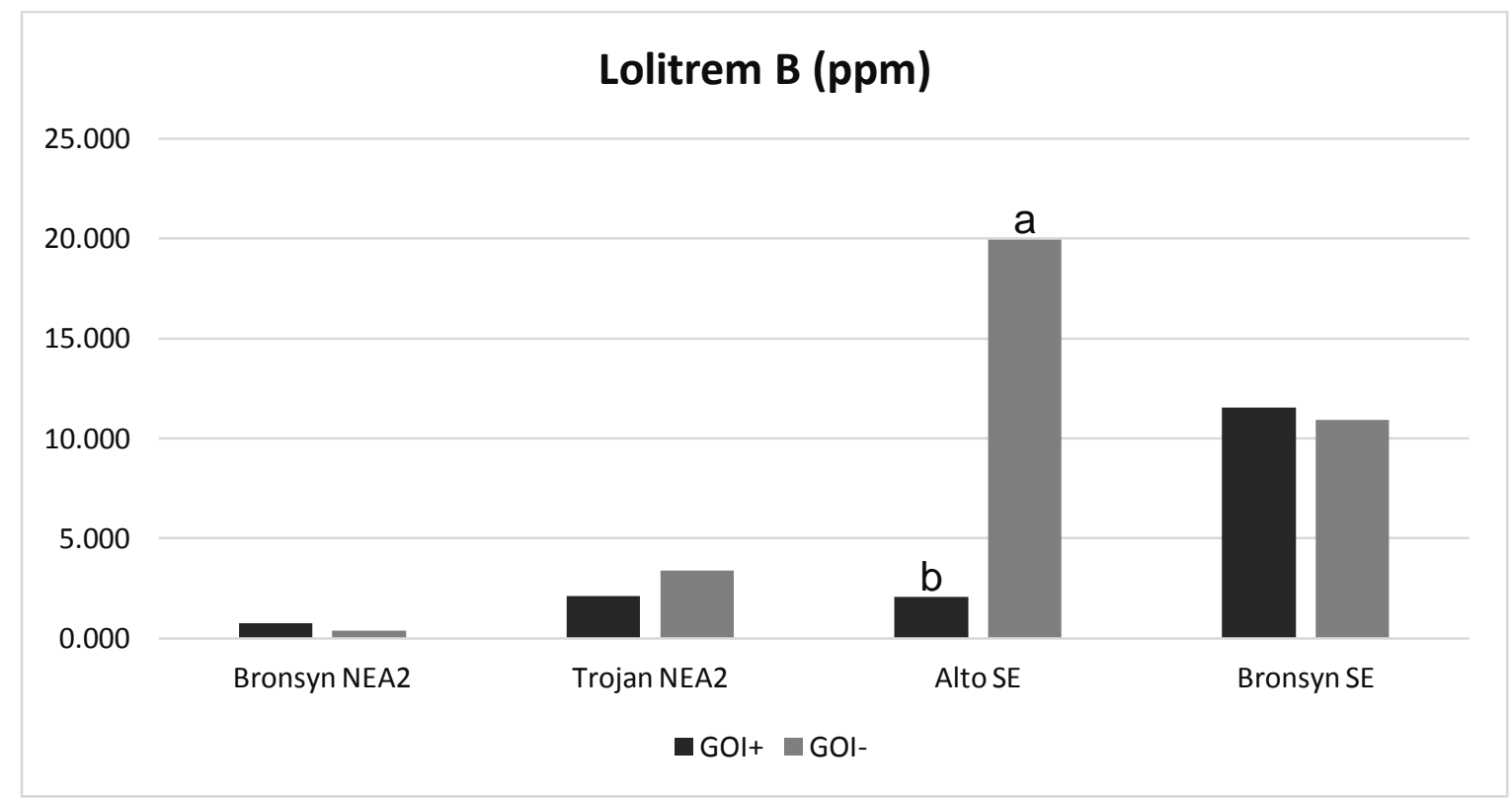

Fig. 2. Lolitrem B concentration of each cultivar-endophyte combination for transgenic lines in dark grey and non-transgenic lines in clear grey. Bars are backtransformed means. $\mathrm{GOI}_{+}=$gene of interest positive; $\mathrm{GOI}-=$ gene of interest negative 


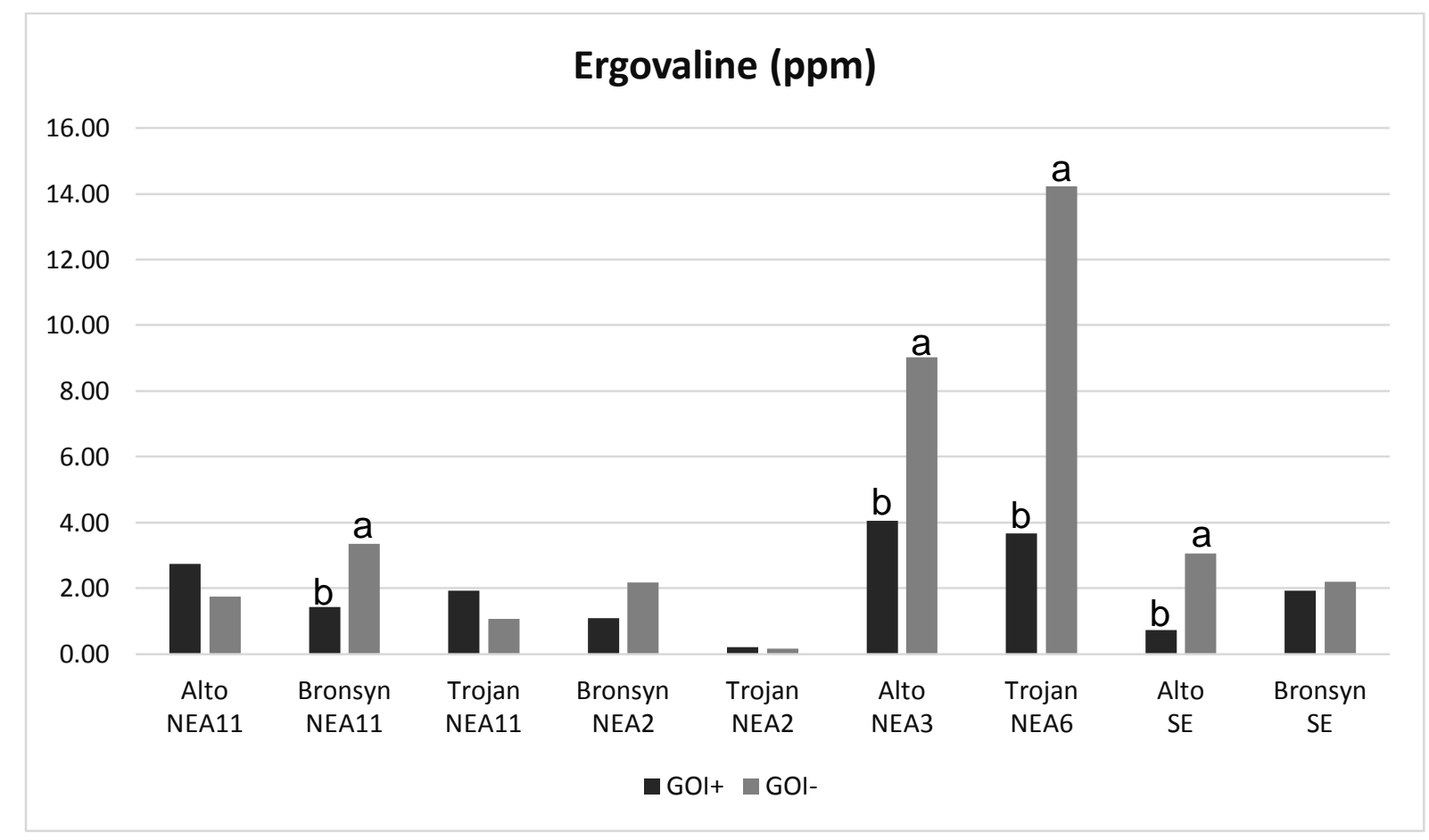

Fig. 3. Ergovaline concentration of each cultivar-endophyte combination for transgenic lines in dark grey and non-transgenic lines in clear grey. Bars are backtransformed means. a $b$ different letters indicate significant differences at $P<0.05$. $\mathrm{GOI}+=$ gene of interest positive; $\mathrm{GOI}-$ = gene of interest negative. 


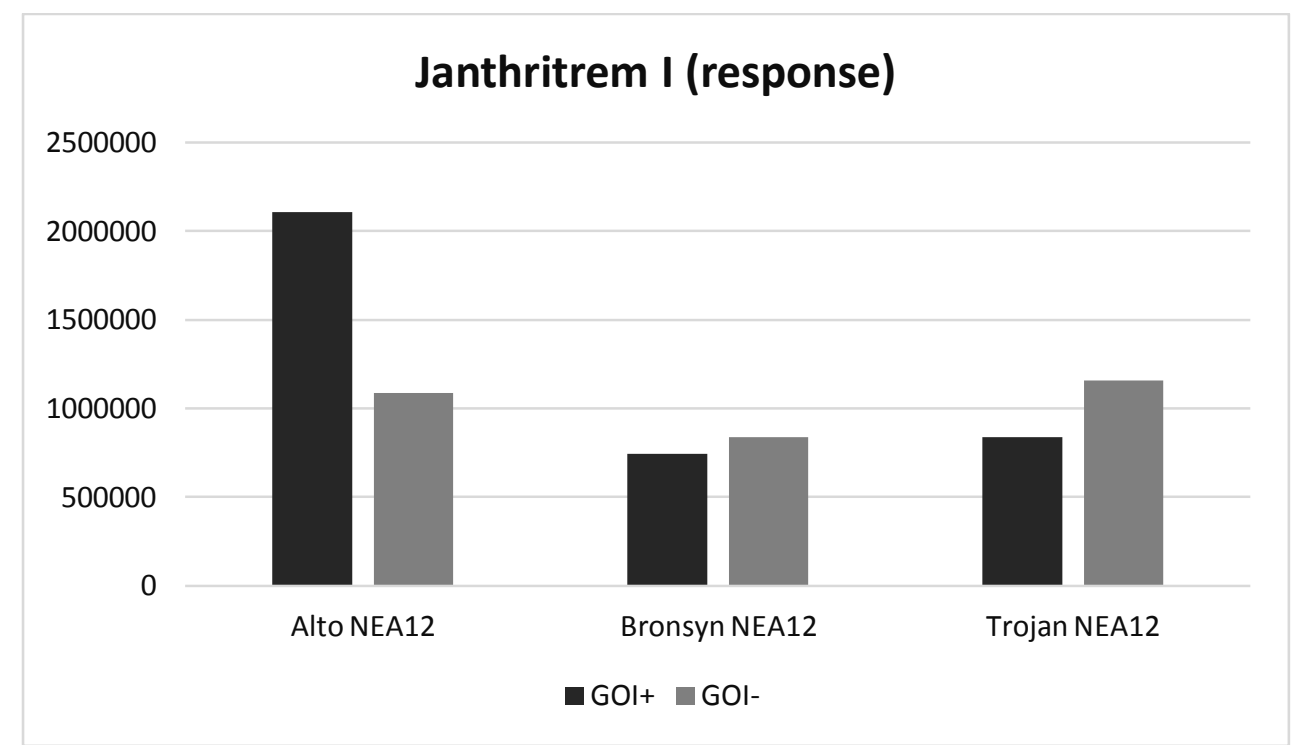

Fig. 4. Janthritrem I response of each cultivar-endophyte combination for transgenic lines in dark grey and non-transgenic lines in clear grey. Bars are back-transformed means. $\mathrm{GOI}+=$ gene of interest positive; $\mathrm{GOI}-$ = gene of interest negative 


\section{Supplement legends}

Figure S1. Plasmid map of transgenic cassette in the event 10 ryegrass genome. The transcriptional direction is indicated with arrow, and the perennial ryegrass rubisco promoter, 1SST-6G-FFT fusion protein gene, and FT4 terminator sequences are shown with dark green, blue, and red arrows, respectively. For designing the SST-FFT fusion protein gene, the terminal codon (TAG) of the perennial ryegrass SST gene was removed.

Table S2. Endophyte incidence in T1/F1 progenies. GOI refers to gene of interest positive (+) or negative (-). Plant No. refers to the number of cultivar-endophyte-gene of interest combination plants used in the study.

Table S3. Oligonucleotide primer sequences to determine transgene presence in perennial ryegrass.

Table S4. Oligonucleotide primer sequences to differentiate between genotypes of endophyte within perennial ryegrass plants.

Table S5. Table of SSR marker details and expected product sizes amplified from different genotypes of endophyte within perennial ryegrass plants. ST: standard toxic.

Table S6 List of endophytes used in this study and their expected alkaloid profiles

Table S7: Back-transformed means. $\mathrm{E}=$ endophyte; $\mathrm{GOI}+=$ gene of interest positive; and GOI- = gene of interest negative. 
Figure S1. Plasmid map of transgenic cassette pGRA000022 in the event 10 ryegrass genome. The transcriptional direction is indicated with arrow, and the perennial ryegrass rubisco promoter, 1SST-6G-FFT fusion protein gene, and FT4 terminator sequences are shown with dark green, blue, and red arrows, respectively. For designing the SST-FFT fusion protein gene, the terminal codon (TAG) of the perennial ryegrass SST gene was removed.

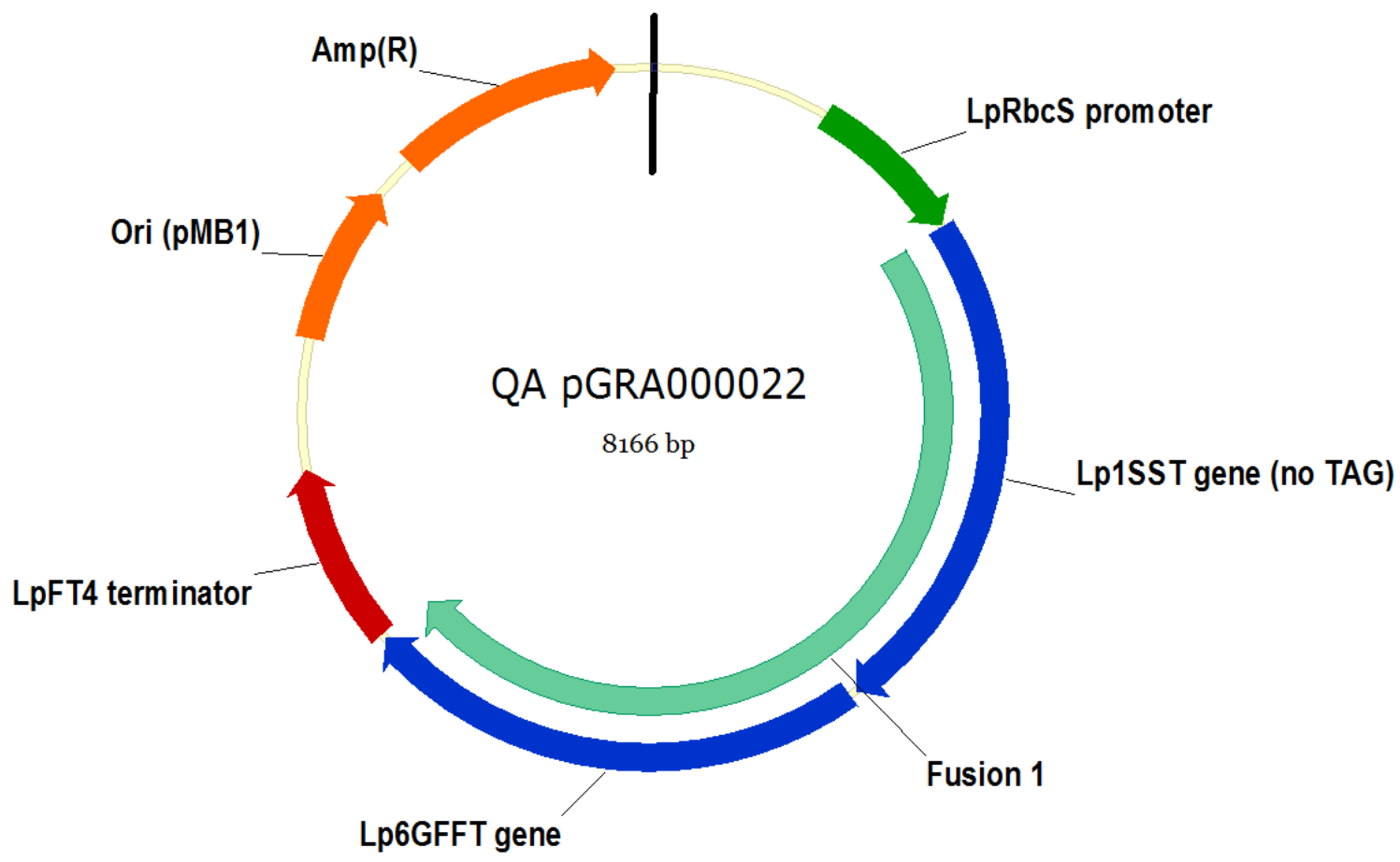


Table S2. Endophyte incidence in $\mathrm{T} 1 / \mathrm{F} 1$ progenies. $\mathrm{GOI}$ refers to gene of interest positive (+) or negative (-). Plant No. refers to the number of cultivar-endophyte-gene of interest combination plants used in the study.

\begin{tabular}{|c|c|c|c|}
\hline Cultivar & Endophyte & GOI & Plant No. \\
\hline \multirow[t]{10}{*}{ Alto } & AR1 & + & 15 \\
\hline & & - & 21 \\
\hline & NEA11 & + & 6 \\
\hline & & - & 10 \\
\hline & NEA12 & + & 4 \\
\hline & & - & 6 \\
\hline & NEA3 & + & 10 \\
\hline & & - & 17 \\
\hline & SE & + & 4 \\
\hline & & - & 9 \\
\hline \multirow[t]{10}{*}{ Bronsyn } & AR1 & + & 6 \\
\hline & & - & 12 \\
\hline & NEA11 & + & 10 \\
\hline & & - & 14 \\
\hline & NEA12 & + & 9 \\
\hline & & - & 6 \\
\hline & NEA2 & + & 6 \\
\hline & & - & 9 \\
\hline & SE & + & 9 \\
\hline & & - & 10 \\
\hline \multirow[t]{9}{*}{ Trojan } & AR1 & + & 12 \\
\hline & & - & 14 \\
\hline & NEA11 & + & 8 \\
\hline & & - & 6 \\
\hline & NEA12 & + & 7 \\
\hline & & - & 11 \\
\hline & NEA2 & + & 10 \\
\hline & & - & 12 \\
\hline & NEA6 & + & 9 \\
\hline
\end{tabular}


Table S3. Oligonucleotide primer sequences to determine transgene presence in perennial ryegrass.

\begin{tabular}{lrrr}
\hline \multicolumn{1}{c}{ Target } & Assay & Forward Primer $\left(5^{`}\right.$-3 $\left.^{\prime}\right)$ & Reverse Primer $\left(5^{`}\right.$-3` $\left.^{\prime}\right)$ \\
\hline LpHisH3 & qPCR & TGCTTGCCCTTCAGGAGGCT & CTGAATGTCCTTGGGCATGAT \\
GOI & qPCR & CCCGCGGTGATTCATGGAG & CGACGACCACCGACAACGC \\
\hline
\end{tabular}


Table S4. Oligonucleotide primer sequences to differentiate between genotypes of endophyte within perennial ryegrass plants.

\begin{tabular}{cll}
\hline SSR Locus & \multicolumn{1}{c}{ Forward Primer $\left(5^{`}-3^{\prime}\right)$} & \multicolumn{1}{c}{ Reverse Primer $\left(5^{`}-3^{\prime}\right)$} \\
\hline NLESTA1QA09 & FAM- & CTAACGATGTATGCGTTTGTTTGG \\
& TGGATATTTTGAAGAATTCCAGG & \\
NLESTA1NGO3 & HEX-CGGGCGCACTTGCTTCTCGG & GCCCCGCAGCCTTGTCGTTG \\
NLESTA1CC05 & NED- & TTGGGACTTTCCAGAGTTGAGCAG \\
& CGCATACACGTTATGAAGCAGAGG &
\end{tabular}


Table S5. Table of SSR marker details and expected product sizes amplified from different genotypes of endophyte within perennial ryegrass plants. ST: standard toxic.

\begin{tabular}{lllll} 
SSR Locus & \multicolumn{1}{c}{ Sensitivity } & \multicolumn{1}{c}{ Repeat Motif } & $\begin{array}{l}\text { Expected } \\
\text { Size AR1 }\end{array}$ & $\begin{array}{c}\text { Expected } \\
\text { Size ST }\end{array}$ \\
& & & & \\
\hline NLESTA1QA09 & Low & $(\mathrm{GA}) 20(\mathrm{G}) 1(\mathrm{GA}) 3$ & 189 & 149 \\
NLESTA1NGO3 & High & $(\mathrm{GTC}) 6$ & 226 & 226 \\
NLESTA1CC05 & Intermediate & $(\mathrm{TGT}) 17$ & 217 & 164 \\
\hline
\end{tabular}


Table S6. List of endophytes used in this study and their expected alkaloid profiles

\begin{tabular}{ccc} 
Endophyte strain & Alkaloid profile & Reference \\
\hline SE & Peramine & \\
& Ergovaline & Christensen, et al. (1993) \\
& Lolitrem B & Siegel, et al. (1990) \\
AR1 & Peramine & Bultman, et al. (2003) \\
NEA2 & Peramine & \\
& Ergovaline & \\
& Lolitrem B & van Zijll de Jong, et al. (2008b) \\
NEA3 & Peramine & \\
& Ergovaline & van Zijll de Jong, et al. (2008a) \\
NEA6 & Peramine & \\
& Ergovaline & van Zijll de Jong, et al. (2008a) \\
NEA11 & Peramine & Kaur, et al. (2015) \\
& Ergovaline & \\
NEA12 & Janthitrem I & Kaur, et al. (2015) \\
& & \\
\end{tabular}


Table S7: Back-transformed means. $\mathrm{E}=$ endophyte; $\mathrm{GOI}+=$ gene of interest positive; and GOl- = gene of interest negative.

\begin{tabular}{|c|c|c|c|}
\hline Trait & Cultivar-E & GOI- & $\mathrm{GOI+}$ \\
\hline \multirow[t]{12}{*}{ Peramine } & Alto-AR1 & 37.229 & 53.118 \\
\hline & BronSyn-AR1 & 41.213 & 35.468 \\
\hline & Trojan-AR1 & 63.774 & 56.553 \\
\hline & Alto-NEA11 & 33.121 & 25.838 \\
\hline & BronSyn-NEA11 & 18.847 & 21.218 \\
\hline & Trojan-NEA11 & 15.868 & 17.771 \\
\hline & BronSyn-NEA2 & 19.755 & 32.394 \\
\hline & Trojan-NEA2 & 7.167 & 9.163 \\
\hline & Alto-NEA3 & 24.329 & 27.338 \\
\hline & Trojan-NEA6 & 8.029 & 21.312 \\
\hline & Alto-SE & 25.234 & 64.218 \\
\hline & BronSyn SE & 43.678 & 38.764 \\
\hline \multirow[t]{4}{*}{ Lolitrem B } & BronSyn-NEA2 & 0.762 & 0.395 \\
\hline & Trojan-NEA2 & 2.105 & 3.394 \\
\hline & Alto-SE & 2.069 & 3.3943 \\
\hline & BronSyn SE & 11.555 & 10.947 \\
\hline \multirow[t]{9}{*}{ Ergovaline } & Alto-NEA11 & 2.749 & 1.742 \\
\hline & BronSyn-NEA11 & 1.430 & 3.345 \\
\hline & Trojan-NEA11 & 1.938 & 1.070 \\
\hline & BronSyn-NEA2 & 1.092 & 2.186 \\
\hline & Trojan-NEA2 & 0.208 & 0.175 \\
\hline & Alto-NEA3 & 4.061 & 9.018 \\
\hline & Trojan-NEA6 & 3.660 & 14.231 \\
\hline & Alto-SE & 0.725 & 3.062 \\
\hline & BronSyn SE & 1.936 & 2.202 \\
\hline \multirow[t]{3}{*}{ Janthritrem } & Alto-NEA12 & 2105366.249 & 1088161.355 \\
\hline & BronSyn-NEA12 & 744151.558 & 839028.539 \\
\hline & Trojan-NEA12 & 839028.539 & 1155449.496 \\
\hline
\end{tabular}




\section{University Library}

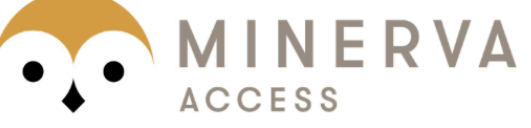

A gateway to Melbourne's research publications

Minerva Access is the Institutional Repository of The University of Melbourne

Author/s:

Giraldo, PA;Elliott, C;Badenhorst, P;Kearney, G;Spangenberg, GC;Cogan, NOI;Smith, KF

Title:

Evaluation of endophyte toxin production and its interaction with transgenic perennial ryegrass (Lolium perenne L.) with altered expression of fructosyltransferases

Date:

2018-10-01

Citation:

Giraldo, P. A., Elliott, C., Badenhorst, P., Kearney, G., Spangenberg, G. C., Cogan, N. O. I. \& Smith, K. F. (2018). Evaluation of endophyte toxin production and its interaction with transgenic perennial ryegrass (Lolium perenne L.) with altered expression of fructosyltransferases. TRANSGENIC RESEARCH, 27 (5), pp.397-407. https:// doi.org/10.1007/s11248-018-0087-9.

Persistent Link:

http://hdl.handle.net/11343/283070 